\title{
Interatrial shunt flow profiles in newborn infants: a colour flow and pulsed Doppler echocardiographic study
}

Satoshi Hiraishi, Youtaro Agata, Koichi Saito, Kohki Oguchi, Hitoshi Misawa, Nobuyuki Fujino, Yasunori Horiguchi, Kimio Yashiro

\begin{abstract}
Interatrial shunt flow profiles in 36 normal term infants were examined serially by colour flow and pulsed Doppler echocardiographic techniques from within an hour of birth to four or five days after birth. Shunt flow across the foramen ovale was detected in 33 normal infants $(92 \%)$ within an hour of birth (mean 40 minutes). The occurrence of interatrial shunting decreased with age, but a shunt signal was still detected in 17 infants $(47 \%)$ on the fourth or fifth day of life, by then the ductus arteriosus had already closed in all the normal infants. The direction of interatrial shunt flow was predominantly left-to-right, but in $64 \%$ there was a coexistent small rightto-left shunt in diastole within an hour of birth; by four to five days it was found in $19 \%$. In the six patients with persistent fetal circulation the direction of the interatrial shunt flow was predominantly right-to-left with biphasic peaks in diastole and systole at the early stage of the disease, and the period of right-toleft shunt flow during each cardiac cycle was significantly longer than that in normal infants examined within 1 hour of birth. In all patients the ductus closed before the foramen ovale. At the time of ductal closure in all patients with persistent fetal circulation right-to-left shunt flow was seen during diastole and its period was still prolonged.
\end{abstract}

These findings suggest that interatrial shunting, predominantly left-to-right, is common in normal newborn infants. Evaluation of the characteristics of the interatrial shunt by Doppler echocardiography may be useful for predicting the progress of or improvement in neonates with persistent fetal circulation.

Dramatic changes occur in the circulation of the newborn infant. In most normal newborn infants the foramen ovale functionally closes within an hour of birth as a result of the increase in pulmonary venous return, decrease in blood flow in the inferior vena cava, and increase in systemic arterial resistance after delivery. ${ }^{12}$ However, a recent Doppler echocardiographic study suggested that in normal neonates, right-to-left shunting occurred during most of diastole, with coexistent left-toright shunting for some time. ${ }^{3}$ In addition, little is known about the prevalence and serial changes in interatrial shunt flow in normal infants because previous studies did not directly analyse interatrial blood flow. ${ }^{3-5}$ Also interatrial haemodynamic function in patients with persistent fetal circulation syndrome is poorly understood.

Therefore, we analysed interatrial shunt flow profiles using colour flow and pulsed Doppler echocardiography to establish (a) the frequency of a patent foramen ovale during normal postnatal life, $(b)$ flow dynamics across the foramen ovale in normal infants and in patients with persistent fetal circulation, and (c) the relation between ductal shunting or closure and interatrial shunt flow profiles.

\section{Subjects and methods \\ SUBJECTS}

We studied 36 term infants with a gestational age of $>38$ weeks. Each was the product of a normal pregnancy, labour, and delivery. Infants were of average size for gestational age, and birth weight ranged from 2600 to $3700 \mathrm{~g}$ (mean $3100 \mathrm{~g}$ ). None had received any medication or supplementary oxygen before the study. All infants had normal findings on physical examination and echocardiographic examination showed that they were free of cardiovascular disease. The initial study was performed within an hour of birth (mean 40 minutes) in all infants and serial studies were performed during the first five days after birth at $3(0.5)$ (mean (SD)), 24 (1), and 109 (8) hours ( 4 to 5 days). These examinations were undertaken when the infants were in a quiet state.

We also studied six term infants with typical persistent fetal circulation and who presented with early cyanosis within 12 hours of birth, with low arterial oxygen tension (under $45 \mathrm{~mm} \mathrm{Hg}$ when inhaling $100 \%$ oxygen) after structural heart disease had been excluded by cross sectional and Doppler echocardiography. ${ }^{6}$ Birth weights ranged from 2400 to $3400 \mathrm{~g}$ (mean $2900 \mathrm{~g}$ ). There was no recognisable pulmonary, haematological, or central nervous system disease in five patients but one had mild pulmonary parenchymal disease caused by meconium aspiration. Initial examinations were performed within 24 hours of birth in all patients and serial studies were performed one or two times a day until all clinical findings disappeared.

\section{COLOUR FLOW AND DOPPLER} ECHOCARDIOGRAPHIC EXAMINATIONS All infants were studied with a commercially 
available system (Hewlett-Packard, Model $77020 \mathrm{AC}$ ) with a $5 \mathrm{MHz}$ shallow focus or 3.5 $\mathrm{MHz}$ transducer. For analysis we used the image that best demonstrated the colour flow imaging of transatrial flow. This was most often obtained from the subxiphoid approach as described previously. ${ }^{4}$ The lower parasternal approach was also attempted in some infants. In addition, the entire length of the ductus arteriosus was visualised from the high parasternal approach. ${ }^{7}$ For Doppler colour flow imaging, flow directed toward the transducer was conventionally coded as red whereas flow directed away from the transducer was blue. Variations in velocity were represented by the brightness and intensity of the colour. For colour flow imaging the gain was initially reduced and then progressively increased until an acceptable colour image was obtained. Interatrial left-to-right shunting was judged to be present when red, yellow, or mosaic signals crossed the atrial septum and extended into the right atrium. Right-to-left shunting was considered to be present if blue or mosaic signals crossed the atrial septum and extended into the left atrium. Ductal leftto-right shunting was considered to be present if red, yellow, or mosaic signals were seen across the ductus from the descending aorta to the main pulmonary artery. Right-to-left ductal shunting was judged to be present if blue or mosaic signals crossed the ductus from the main pulmonary artery to the descending aorta.

When colour mapping showed interatrial or ductal shunting the findings were confirmed by pulsed Doppler analysis, which indicated the direction of the flow across these orifices. The sample volume was placed on the colour Doppler echocardiographic shunt flow signal. Doppler profiles and simultaneous electrocardiograms were recorded at $50-100 \mathrm{~mm} / \mathrm{s}$ and were stored on video tape for later playback and analysis in stop frame mode. When there was a bi-directional pattern at the site of the interatrial communication the time intervals were measured as described elsewhere. ${ }^{8}$ In brief, the turning point from the right-to-left to the left-to-right shunt was designated as $T_{1}$ and the turning point from the left-to-right to the right-to-left shunt as $T_{2}$ (fig 1 ). The ratio of the $T_{1}-T_{2}$ interval to the $R R$ interval of the electrocardiogram $\left(T_{1}-T_{2} / R R\right)$ was calculated and a mean taken from the recordings of 10 consecutive beats.

\section{STATISTICAL ANALYSIS}

We used non-parametric techniques to analyse serial changes in the frequency of interatrial shunting and Student's $t$ test for differences in mean values between the two groups. A probability value of $<0.05$ was regarded as significant.

\section{Results}

NORMAL NEWBORN INFANTS

Within an hour of birth left-to-right shunt flow was detected in 10 infants $(28 \%)$ and bi-directional shunt flow in $23(64 \%)$ (table, fig 2$)$. The proportion in whom the foramen ovale was functionally closed did not change within three hours of birth but increased significantly from three to 24 hours $(p<0.01)$. There had been a further increase in the functional closure by the fourth and fifth days of life, but $10(28 \%)$ infants still had a left-to-right shunt signal and seven $(19 \%)$ a bi-directional one. The ductus arteriosus was patent three hours after birth in all infants and it closed functionally in $52 \%$ at 24 hours of life. By the fourth to the fifth day of life, there had been spontaneous functional closure of the ductus in all infants.

\section{ANALYSIS OF INTERATRIAL SHUNT FLOW} DYNAMICS IN HEALTHY NEWBORN INFANTS A left-to-right shunt signal was recorded in systole and early diastole (fig 2). A slight rightto-left shunt signal was noted in diastole, mostly in atrial systole; during three examinations in two infants a right-to-left shunt signal was noted in both diastole and systole. In 23 infants with a bi-directional shunt flow within an hour of birth the mean $T_{1}-T_{2} / R R$ ratio ranged from 0.68 to 0.95 (mean 0.85 ) (fig 3 ).
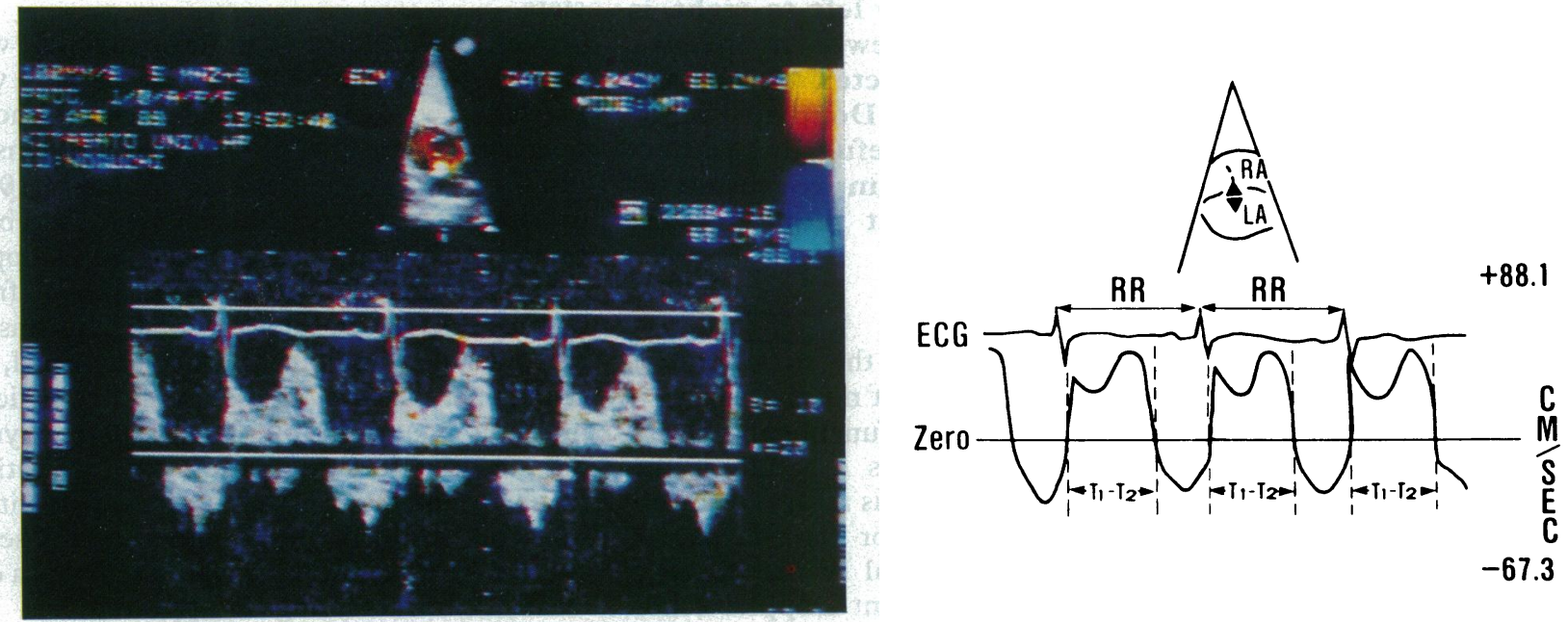

Figure 1 Interatrial shunt flow profile determined by Doppler echocardiography. The sample volume was placed at the site of the foramen ovale. Doppler spectral display above the zero line represents left-to-right flow and that below the zero line right-to-left. The duration of left-to-right interatrial flow $\left(T_{1}-T_{2}\right)$ was measured and expressed as the ratio to the $R R$ interval of the electrocardiogram $\left(T_{1}-T_{2} / R R\right)$. ECG, electrocardiogram; $L A$, left atrium; $R A$, right atrium. 

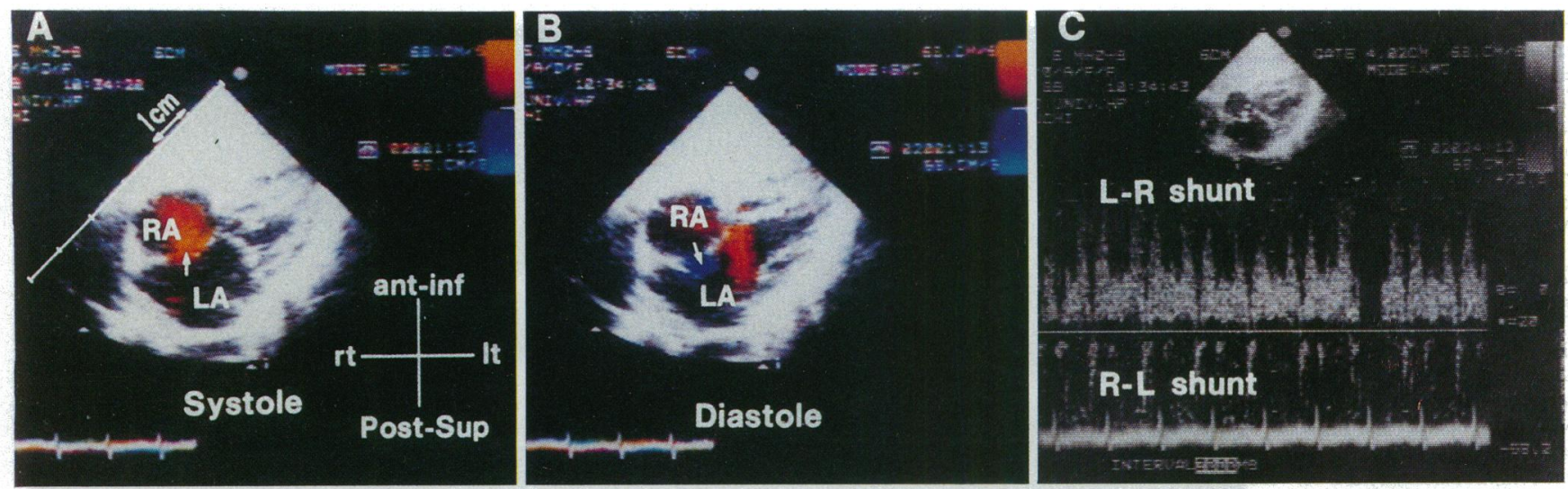

Figure 2 Colour flow and pulsed Doppler echocardiograms from a normal infant 30 minutes after delivery. (A) Subxiphoid view showing transatrial red signal (arrow) during systole, which is indicative of left-to-right shunt flow. (B) Note the blue signal (arrow) crossing from right atrium to left atrium in diastole. (C) Doppler signal showing that the direction of shunt flow is predominantly left-to-right ( $L-R$ ), which is represented as Doppler signal toward the transducer. There was a small amount of right-to-left $(R-L)$ shunt flow (Doppler signal away from transducer) of short duration in atrial systole. $R A$, right atrium; $L A$, left atrium; ant-inf, anterior-inferior; post-sup, posterior-superior; rt, right; $l t$, left.

Occurrence and direction of interatrial shunt flow

\begin{tabular}{llllll}
\hline & \multicolumn{1}{l}{ Age after birth } \\
\cline { 2 - 6 } Direction of shunt flow & $20-60(\min )(n(\%))$ & $2-4(h)(n(\%))$ & $23-26(h)(n(\%))$ & $4-5($ days $)(n(\%))$ \\
\hline No shunt & 3 & $(8)$ & $4(11)$ & $13(36)$ & $19(53)$ \\
Left-to-right shunt & $10(28)$ & $13(36)$ & $12(33)$ & $10(28)$ & $7(19)$ \\
Bi-directional shunt & $23(64)$ & $19(53)$ & $11(31)$ & $(n)$ \\
\hline
\end{tabular}

PATIENTS WITH PERSISTENT FETAL CIRCULATION At the initial examination the direction of interatrial shunt flow was predominantly rightto-left. The right-to-left shunt signal was

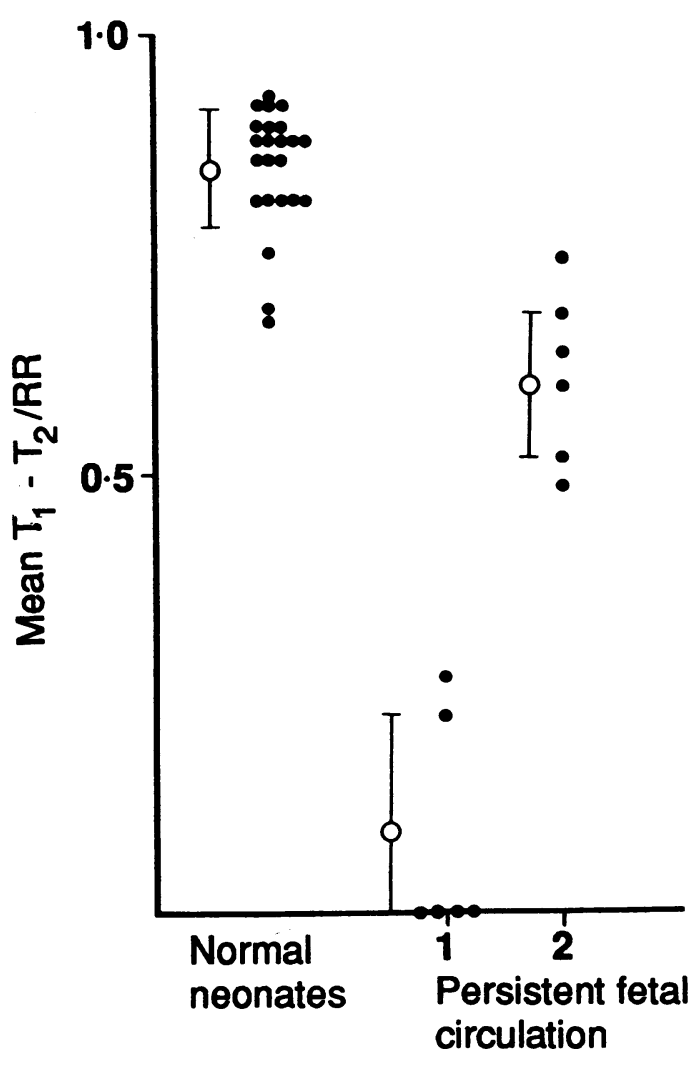

Figure $3 T_{1}-T_{2} / R R$ ratio in 23 normal infants with a bi-directional shunt flow and six patients with persistent fetal circulation (PFC) associated with considerable hypoxaemia (PFC-1) and ductal closure (PFC-2). The ratio of $T_{1}-T_{2} / R R$ was smaller in $P F C-1$ than in

normal infants $(p<0.01)$ and the value in the PFC-2 lay between values in the other two groups. The bars show mean $(1 S D)$ recorded in both diastole and systole (fig 4). In two patients, small left-to-right shunt flow was detected in late systole. During the same period, the direction of the shunt flow within the ductus was predominantly right-to-left during systole and a small left-to-right shunt flow was detected during diastole in five patients. In all infants the ductus closed spontaneously between 24 hours and 120 hours after birth. At the time of ductal closure, interatrial shunt flow pattern was bi-directional and rightto-left shunt flow was detected in diastole in all six patients. Inspired oxygen was needed to maintain arterial oxygen tension between 50 and $60 \mathrm{~mm} \mathrm{Hg}$ and the fraction of inspired oxygen ranged from 0.4 to 0.8 in each patient. Figure 3 shows that the $T_{1}-T_{2} / R R$ ratio was significantly lower in the early phase of persistent fetal circulation than at the time of the ductal closure $(\mathrm{p}<0.01)$ and both values were also significantly lower than those seen within an hour of birth in normal infants $(p<0.01)$. These bi-directional shunt patterns changed to left-to-right flow between the sixth and 20th day of life, and functional closure of the foramen ovale was noted in four patients by one month.

\section{Discussion}

The data presented in this study showed that an interatrial shunt, predominantly left-to-right, was common in normal newborn infants. Colour flow mapping clearly distinguished between interatrial left-to-right shunting and flow in the superior vena cava. The results of colour flow mapping were confirmed by pulsed Doppler spectral analysis. The frequency of interatrial shunting did not change within the first three hours of birth, but it was significantly decreased from three to 24 hours after birth. 
Figure 4 Colour Doppler echocardiograms from a patient with persistent fetal circulation. The transatrial blue signal, which is indicative of right-to-left shunt flow, was recorded in diastole. Note the mosaic signal (arrow) crossing to the foramen ovale in systole, indicating aliaising. Combined pulsed Doppler flow mapping and cowtinuous Doppler continuous Doppler blue signal originated from tricuspid regurgitant jet with high velocity of $3 \cdot 5$ $\mathrm{m} / \mathrm{s}$. TV, tricuspid valve; $M V$, mitral valve; $R A$, right atrium; $L A$, left atrium.
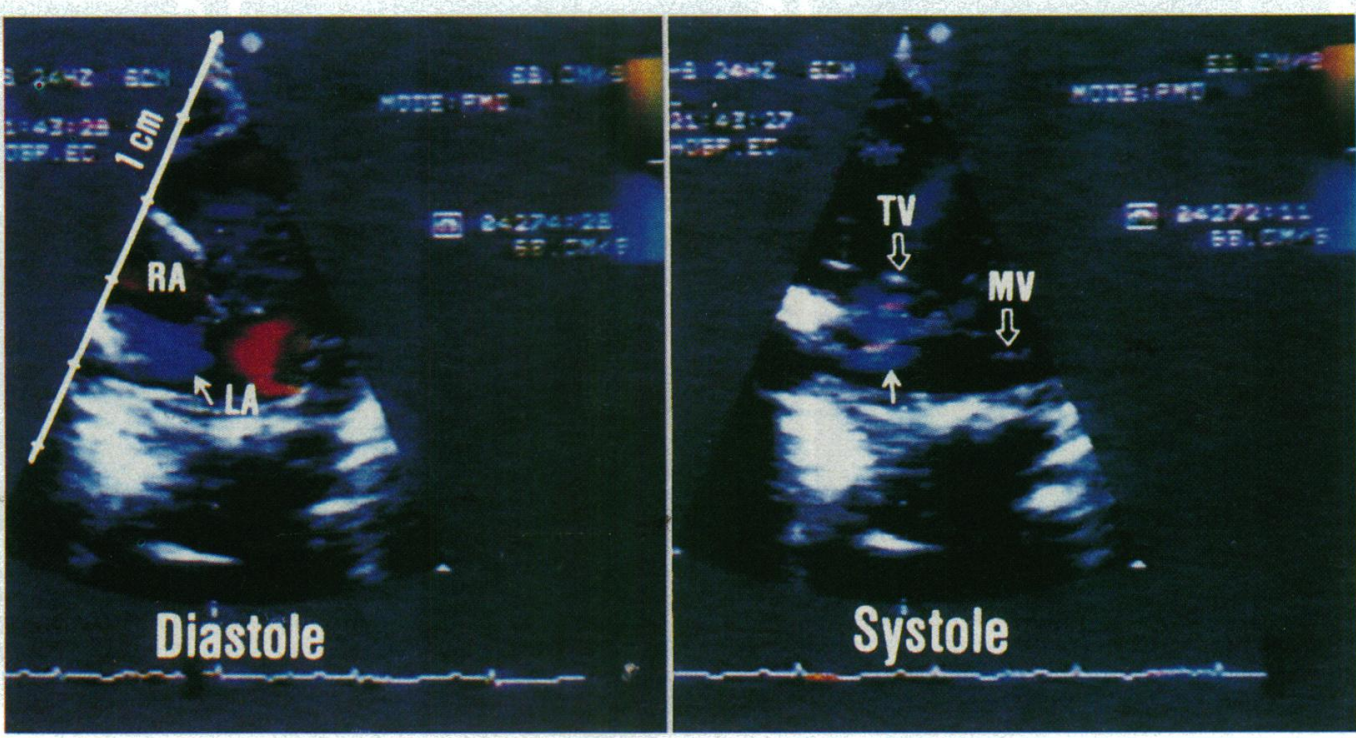

Drayton and Skidmore reported that ductal left-to-right shunt flow of $62 \mathrm{ml} / \mathrm{kg} /$ minute in term infants ( $95 \%$ confidence interval 43 to 82 ) shortly after birth decreased rapidly over the first 12 hours. ${ }^{9}$ This result was consistent with the time course of changes in the morphology and flow patterns in the ductus arteriosus. ${ }^{1011}$ From these observations, it seems that the ductal left-to-right shunting in early postnatal life increases the frequency and magnitude of the left-to-right shunting through the foramen ovale. However, this mechanism does not explain the finding that interatrial shunt flow was detected in $47 \%$ of our subjects in the fourth to fifth day of life when the ductus had already closed in all infants. An earlier study ${ }^{4}$ and our study found that the patent foramen ovale was either a redundant flap valve of the septum primum or a septal drop out at the superior rim of the septum primum. Others also found that patent foramina ovale were of normal size with unduly short or lax valves or were oversized with a normal sized valve. ${ }^{12}$ Incompetence of the foramen ovale could occur if the development of various portions of the atrial septum was unbalanced, even in the absence of left atrial enlargement, ${ }^{13}$ left sided lesions, and left ventricular failure. ${ }^{14}$

We assessed the phase and the duration of interatrial left-to-right or right-to-left shunting during each cardiac cycle from simultaneous recordings of the Doppler determined flow velocity pattern and the electrocardiogram. In most normal infants left-to-right shunting was dominant and slight right-to-left shunt flow was frequently noted in diastole; however, right-to-left shunt was seen in both diastole and systole in two infants with moderate tricuspid regurgitation. On the other hand, in all six patients with persistent fetal circulation, right-to-left shunting was dominant with biphasic peaks in diastole and in systole; but in two infants there was a small left-to-right shunt flow in later systole. We did not monitor respiration, and respiration especially mechanical ventilation, might have an effect on the interatrial shunt flow pattern. All six infants with persistent fetal circulation, however, showed conversion from dominant right-toleft shunting to bi-directional shunting during intubation and ventilation, and two had pure left-to-right shunting immediately before the extubation. These manoeuvres seemed to have little effect upon changes in the flow patterns in our patients.

The interatrial pressure gradient, which can determine the direction and the phase of shunt flow ${ }^{15}$ may be affected by ( $a$ ) the difference in distensibility of the right and left ventricles, (b) the capacitance of the systemic and pulmonary venous systems, $(c)$ tricuspid regurgitation, and/or $(d)$ persistence of a right-to-left or leftto-right shunt at the level of the ductus arteriosus. Analysis of the filling patterns of the right and left ventricles in normal neonates ${ }^{316}$ suggested that the right ventricle becomes less distensible in the neonatal period and that this may cause diastolic interatrial shunting. If this is an effect of raised pulmonary resistance, then the pulmonary artery hypertension associated with persistent fetal circulation should predispose to an increase in diastolic right-to-left interatrial shunt flow as seen in our study. On the other hand, in an earlier cineangiographic study of ventricular volume in 10 patients with persistent fetal circulation we found that a decrease in pulmonary blood flow reduced the preload of the left ventricle. ${ }^{17}$ We also found that a regurgitant tricuspid jet crossed the foramen ovale and entered the left atrium in two normal infants and four with persistent fetal circulation. These observations raise the possibility that systolic right-to-left shunting results from a smaller capacity of the pulmonary venous system than that of systemic venous system, from tricuspid regurgitation, or from both.

All six patients with persistent fetal circulation responded to conventional treatments such as infusion of tolazoline hydrochloride and hyperventilation. The ductus arteriosus closed before the foramen ovale in all six patients. At the time of the ductal closure the interatrial shunt flow pattern was bi-directional and the duration of diastolic right-to-left shunt flow was still longer than in normal infants. At 
this stage these patients had mild to moderate hypoxaemia. Our data indicate that relatively reduced distensibility of the right ventricle may persist after ductal closure, resulting in interatrial right-to-left shunting in diastole. The reduced distensibility of the right ventricle may be related to the persistence of relatively high pulmonary arterial pressure seen even after ductal closure in infants with persistant fetal circulation. ${ }^{18}$

Evaluation of interatrial shunting by Doppler echocardiography depends on this knowledge of the characteristics of interatrial shunting in normal newborn infants. The Doppler technique can be useful in assessing the severity and course of persistent fetal circulation.

This work was supported by a grant from the Kitasato University Foundation and a Grant-in-Aid for General Scientific Research from the Ministry of Education, Science and Culture in Japan.

We thank all members of the neonatal intensive care unit, Miss Harumi Kawai, and Mr Masahiro Ohe.

1 Gessner I, Krovetz LJ, Benson RW, Prystowsky H, Stenger V, Eitzman DV. Hemodynamic adaptations in , Stenger born infant. Pediatrics 1965;36:752-62.

2 Arcilla RA, Oh W, Wallgren G, Hanson JS, Gessner IH Lind J. Quantitative studies of the human neonatal circulation II. Hemodynamic findings in early and late clamping of the umbilical cord. Acta Paediatr Scand Suppl 1967:179:23-42

3 Steinfeld L, Almeida OD, Rothfeld EL. Asynchronous atrioventricular valve opening as it relates to right to left interatrial shunting in the normal newborn. $\mathrm{J} \mathrm{Am} \mathrm{Coll}$ Cardiol 1988;12:712-8.

4 Bierman FZ, Williams RG. Subxiphoid two-dimensional imaging of the interatrial septum in infants and neonates with congenital heart disease. Circulation 1979;60:80-90.

5 Kupferschmid C, Lang D. The valve of the foramen ovale in interatrial right-to-left shunt: echocardiographic cine- angiocardiographic and hemodynamic observations. Am J Cardiol 1983;51:1489-94.

6 Gersony WM. Neonatal pulmonary hypertension: clinical review. In: Doyle EF, Engle MA, Gersony WM, Rashkind WJ, Talner NS, eds. Pediatric cardiology. New York, Berlin, Heidelberg, Tokyo: Springer-Verlag, 1986: 876-9.

7 Hiraishi S, Horiguchi Y, Misawa H, et al. Noninvasive Doppler echocardiographic evaluation of shunt flow dynamics of the ductus arteriosus. Circulation 1987;75: 1146-53.

8 Satomi G, Nakazawa M, Takao A, et al. Blood flow pattern of the intraatrial communication in patients with complete transposition of the great arteries: a pulsed Doppler echocardiographic study. Circulation 1986;73:95-9.

9 Drayton MR, Skidmore R. Ductus arteriosus blood flow during first 48 hours of life. Arch Dis Child 1987;62: during first.

10 Hiraishi S, Misawa H, Oguchi K, et al. Two-dimensional Doppler echocardiographic assessment of closure of the
Dophention ductus arteriosus in normal newborn infants. $J$ Pediatr 1987;111:755-60.

11 Hiraishi S, Misawa H, Saito K, et al. The relationship between the morphology and flow patterns in the ductus arteriosus of newborn infants under physiologic conditions and with increased oxygen inspiration. J Jpn Pediatr Soc 1988;92:1259-63 [in Japanese].

12 Edwards JE. Malformations of the atrial septal complex. In: Gould SE, ed. Pathology of the heart and blood vessels, 3rd ed. Springfield Illinois: Charles C Thomas, 1968:262-79.

13 Rudolph AM, Mayer FE, Nadas AS, Grosse RE. Patent ductus arteriosus: a clinical and hemodynamic study of 23 patients in the first year of life. Pediatrics 1958;22: 892-904.

14 Pagtakhan RD, Hartmann AF Jr, Goldring D, Kissane J. The valve-incompetent foramen ovale: a report on seven infants with left-to-right atrial shunt. J Pediatr 1967;
infalvent infants with

15 Minagoe S, Tei C, Kisanuki A, et al. Noninvasive pulsed Doppler echocardiographic detection of the direction of shunt flow in patients with atrial septal defect: usefulness of the right parasternal approach. Circulation 1985;71: $745-53$

16 Riggs TW, Rodriguez R, Snider R, et al. Doppler echocardiographic evaluation of right and left ventricular diastolic function in normal neonates. J Am Coll Cardiol 1989;13:700-5.

17 Hiraishi S. Ventricular volume variables in patients with persistent fetal circulation syndrome. In: Doyle EF, Engle MA, Gersony WM, Rashkind WJ, Talner NS, eds. Pediatric cardiology. New York, Berlin, Heidelberg, Tokyo: Springer-Verlag, 1986:885-8.

18 Musewe NN, Poppe D, Smallhorn JF, et al. Doppler echocardiographic measurement of pulmonary artery pressure from ductal Doppler velocities in the newborn. J Am Coll Cardiol 1990;15:446-56. 